\title{
O papel das aceleradoras para o desenvolvimento das startups e do empreendedorismo no Brasil
}

\section{The role of accelerators for the development of startups and entrepreneurship in Brazil}

\author{
John Jairo Garcia Arcentales ${ }^{1}$, Priscila Machado Borges Sena ${ }^{2}$, Nelma Camelo de Araujo ${ }^{3}$ \\ ${ }^{1}$ Universidade Federal de Alagoas (UFAL), Maceio, Alagoas, Brasil. ORCID: https://orcid.org/0000-0002-4022-4741 \\ ${ }^{2}$ Federação Brasileira de Associações de Bibliotecários, Cientistas da Informação e Instituições, São Paulo, SP, Brasil. ORCID: \\ https://orcid.org/0000-0002-5612-4315 \\ ${ }^{3}$ Universidade Federal de Alagoas (UFAL), Maceio, Alagoas, Brasil. ORCID: https://orcid.org/0000-0002-4892-7484
}

Autor para correspondência/Mail to: John Jairo Garcia Arcentales, john.ja12@hotmail.es

Recebido/Submitted: 23 de março de 2021; Aceito/Approved: 01 de junho de 2021

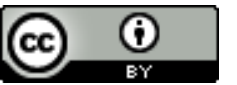

Copyright (C) 2021 Garcia Arcentales, Sena \& Araujo. Todo o conteúdo da Revista (incluindo-se instruções, política editorial e modelos) está sob uma licença Creative Commons Atribuição 4.0 Internacional. Ao serem publicados por esta Revista, os artigos são de livre uso em ambientes educacionais, de pesquisa e não comerciais, com atribuição de autoria obrigatória. Mais informações em http://revistas.ufpr.br/atoz/about/submissions\#copyrightNotice.

\begin{abstract}
Resumo
Introdução: as aceleradoras de startups têm um papel fundamental no ecossistema de empreendedorismo, permitindo formas diferentes de desenvolver novos produtos e serviços, por meio da inovação. Nesta pesquisa o objetivo foi analisar as startups apresentadas no site startupbase.com, mapeando a influência delas no cenário brasileiro. Método: a partir de pesquisa exploratória descritiva, com análise qualitativa dos dados, foram analisadas 13.297 startups. Resultados: nove startups analisadas são unicórnios com investimentos de mais de nove bilhões em cinco anos na economia brasileira (2015-2020). Conclusão: percebeu-se que por meio da inovação, produtos e serviços foram dinamizados, sendo a mecanização de processos o primeiro passo utilizado pelas novas empresas emergentes, mas nem todos os processos de mecanização levam à criação de tecnologia. Para que isso ocorra, é necessário o uso de ferramentas corretas e a disponibilização de informações estratégicas para mudanças adequadas.
\end{abstract}

Palavras-chave: Aceleradoras; Startups brasileiras; Startups.

\begin{abstract}
Introduction: startup accelerators play a fundamental role in the entrepreneurship ecosystem, allowing different ways to develop new products and services through innovation. This research analyzes the startups presented on the startupbase.com website, mapping their influence in the Brazilian scenario. Method: it analyses 13.297 startups based on exploratory, descriptive research with qualitative data analysis. Results: nine startups are unicorns with investments of more than nine billion in five years in the Brazilian economy (2015-2020). Conclusion: it was noticed that through innovation, products and services were streamlined, with the mechanization of processes being the first step used by new emerging companies, but not all mechanization processes lead to the creation of technology so that this occurs it is necessary to use the right tools and the availability of strategic information for appropriate changes.
\end{abstract}

Keywords: Accelerators; Brazilian startups; Startups.

\section{INTRODUÇÃO}

As startups têm um caminho de evolução muito competitivo e incerto, que é enfrentado de forma contínua, tendo que lidar com diversas situações para as quais os empreendedores em muitos casos não estão preparados, tais como: a) patentear sua ideia, produto ou serviço; b) criar grupos de trabalho de acordo com as necessidades nas etapas de seu empreendimento; e buscar capital de investimentos (Shenkoya, 2020).

O papel das aceleradoras de startups destaca-se junto aos empreendedores por conectá-los com investidores e parceiros estratégicos que podem auxiliar a ter um crescimento saudável no seu empreendimento. Segundo Travers e Teixeira (2017), são organizações que auxiliam as empresas do tipo startups, em decorrência da instabilidade que possuem no início, desde a falta de financiamento a problemas jurídicos.

O ecossistema de startups no Brasil tem potencial de conquistar o cenário de empreendedorismo digital a nível mundial, devido aos grandes hubs de inovação. Um hub de inovação é um local onde as startups têm possibilidades de desenvolver suas novas ideias. Objetivo é que esses empreendedores - com alta capacidade de crescimento e constantemente relacionados com tecnologia - "(...) possam trabalhar e também conhecer e fazer trocas com investidores, grandes empresas e outras startups" (Distrito, 2019).

As pessoas estão em constante aprendizado. Nesse sentido, os empreendedores precisam se capacitar para gerir bem seu empreendimento, conhecer o ambiente do seu negócio, os investimentos necessários e seu público-alvo. Políticas adequadas ajudam a implementar um ambiente saudável e estimulante para o empreendedorismo. Nos Estados Unidos, onde as empresas e o empreendedorismo são vistos como um bem-estar social e existem incentivos ao empreendedorismo (Shane, 2020), uma grande percentagem de adultos de 18 a 64 anos estão envolvidos em algum tipo de atividade empresarial (Friedman \& Aziz, 2012). 
No Brasil, de acordo com Endeavor ${ }^{1}$ (2016), em geral, os brasileiros são favoráveis à atividade empreendedora e têm uma visão positiva, mas apenas $19 \%$ demonstraram interesse em abrir um novo negócio nos próximos cinco anos. Isso pode ser constatado pelo fato de que, em 2015 , entre $70 \%$ e $80 \%$ dos brasileiros concordavam em abrir um negócio, porém, em momentos de crises, a vocação empreendedora tende a aumentar por necessidade de sobrevivência.

A produção, a distribuição e o acesso à informação estão no centro da nova economia. A mudança terminológica de sociedade da informação para sociedade do conhecimento sinaliza que o conteúdo, e não a tecnologia da informação, é o principal desafio tanto para a economia quanto para a sociedade em geral (Capurro \& Hjørland, 2007). Ante a esse contexto, o objetivo neste artigo é analisar as startups brasileiras apresentadas no site startupbase.com, mapeando a influência delas no cenário brasileiro.

\section{EMPREENDEDORISMO NO BRASIL POR MEIO DAS STARTUPS}

Embora as crises tragam necessidades substanciais para a população, trazendo-as para o mundo do empreendedorismo, sem as ferramentas necessárias para alcançar o sucesso de seus empreendimentos ou pelo menos chegar a uma etapa de empreendedores estabelecidos, que têm negócios com mais de três anos e meio, é temerária a abertura de um empreendimento (Sebrae Nacional, 2016).

Dados da pesquisa da Global Entrepreneurship Monitor evidenciam que 25\% das empresas criadas no Brasil encerraram suas atividades antes de completar um ano, e 50\% delas encerraram suas atividades antes de completar quatro anos (Sebrae Nacional, 2016). Especificamente, as tecnologias digitais oferecem possibilidades de novas práticas que proporcionam oportunidades empresariais e permitem o desenvolvimento de novos modelos de negócios (Gregori \& Holzmann, 2020). As atividades de empreendedorismo podem gerar crescimento, mudança tecnológica e facilitação do processo de globalização, aumentando as vantagens competitivas num mercado emergente como o Brasil.

Nessa perspectiva, as startups, como empresas recém-criadas, até mesmo rudimentares ou ainda em período de composição, que contam com projetos promissores, relacionados à pesquisa e desenvolvimento de ideias inovadoras com custos iniciais baixos, com alta perspectiva de escala, apresentando expectativa de crescimento quando se concretizam de fato (Sena, 2020), tornam-se elemento favorável ao empreendedorismo e desenvolvimento econômico de um país.

Ressalta-se a importância de avaliar quais são as empresas emergentes digitais com vantagens tecnológicas que obtêm maiores rentabilidades econômicas durante seu crescimento. Dentro dos ecossistemas de empreendedorismo digitais existem atores e ações que qualificam o desempenho das startups e estimulam seus desenvolvimentos, conforme descrição na Tabela 1.

\begin{tabular}{cc}
\hline Ator/Ação & Descrição \\
\hline Incubadora & $\begin{array}{c}\text { Executam programas (duração de 1-2 anos) } \\
\text { para auxiliar startups em estágio inicial }\end{array}$ \\
\hline Acelerador & $\begin{array}{c}\text { Promovem programas curtos e intensivos } \\
\text { (duração de } 3 \text { a } 6 \text { meses) para auxiliar as } \\
\text { partidas em estágio comercial }\end{array}$ \\
\hline Co-working & $\begin{array}{c}\text { Fornecem locais para trabalhar e colaborar } \\
\text { com outras startups }\end{array}$ \\
\hline Mentor & $\begin{array}{c}\text { Orientam e treinam fundadores de startups e } \\
\text { membros da equipe para alcançarem as } \\
\text { habilidades necessárias para o }\end{array}$ \\
& desenvolvimento de negócios e produtos \\
\hline Eventos & $\begin{array}{c}\text { Atividades que ocorrem em horários e locais } \\
\text { específicos para fomentar a colaboração e o } \\
\text { compartilhamento de conhecimento }\end{array}$ \\
\hline
\end{tabular}

Tabela 1. Atores e ações que qualificam o desempenho das startups

Com a missão de fomentar o ecossistema empreendedor no Brasil, Abstartups faz parte dessa evolução. Formada em 2011 por um grupo de empreendedores, a associação tem atuado nesses últimos anos em várias frentes de fomento. Destaca-se o trabalho que desenvolvem os aceleradores de startups dentro do processo de crescimento e expansão. Abstartups desenvolveu a maior premiação do ecossistema de startups e inovação no Brasil chamada Startup Awards em que se premia há oito anos (Associação Brasileira de Startups, 2021).

\footnotetext{
${ }^{1}$ Endeavor é a maior organização de apoio a empreendedorismo e empreendedores de alto impacto. Mais informações em: https://endeavor.org.br/.
} 
Como intermediárias entre as startups e o cenário complexo de recursos econômicos e digitais, a importância das aceleradoras no interior do ecossistema das startups reside na capacitação dos recursos humanos, unindo a educação para o empreendedorismo e o conhecimento das startups. Processos de tutoria ajudam no desenvolvimento regional onde a maioria dos programas termina com um "Demo Day", de tal forma que os fundadores de startups apresentam os seus conceitos de negócio a um grande público de investidores com a possibilidade de se tornarem unicórnios digitais (Lamine et al., 2018).

As aceleradoras representam componentes-chave para impulsionar com inovação a economia local, em virtude de que uma startup em fase inicial é uma empresa em que um inovador está tentando garantir fundos para fazer a mudança necessária de uma inovação para uma tecnologia (tecnologia com valor comercial), o uso de tecnologias digitais leva à captura de valor multidimensional, pois permite complementaridades de impacto, a escalabilidade do valor socioambiental e o transbordamento de valor (Gregori \& Holzmann, 2020).

Porém, de acordo com Shenkoya (2020), os atributos que fazem diferença nas aceleradoras são sem dúvida seu sistema de valor (a soma de todos os produtos, serviços e custos associados ao suporte a startups) e seus modelos de negócios (a estrutura comercial dos aceleradores que os ajuda a atingir seus objetivos).

\section{ACELERADORAS DE STARTUPS}

De acordo com os alinhamentos de cada uma das aceleradoras de startups, Yin e Luo (2018) concluíram que a especialização setorial dos aceleradores é um fator-chave, pois determina seu desempenho. Além disso, alguns pesquisadores que publicam conteúdo sobre startups concordam que existem duas formas para se avaliar o desempenho destas organizações: a) o volume das vendas e a quantidade de clientes pagantes; e b) a atividade dos investidores. Corroborando em relação ao indicador volume de vendas, mesmo que não se deva presumir que obter um desempenho financeiro superior seja o principal objetivo da gestão das empresas, a segunda variável representa um aspecto central do desempenho de um negócio (Morgan, 2012).

Existem também grandes diferenças em termos do montante de capital próprio que um acelerador de startup tem como retorno para o financiamento. As participações máximas de capital próprio variam entre $0 \%$ e $15 \%$, com uma média de 6,1\% (Cohen, Fehder, Hochberg, \& Murray, 2019).

Estas diferenças têm um claro impacto nos tipos de empresas no conjunto de aplicações, mas podem também afetar a estratégia de sobrevivência a longo prazo de um acelerador. Para obter lucros, os aceleradores devem proporcionar retornos favoráveis aos seus investidores, enquanto os aceleradores sem fins lucrativos têm de procurar continuamente o financiamento externo de empresas, fundações e governos.

A sustentabilidade e o alinhamento destas diferentes fontes de capital dependem, em grande medida, do objetivo global do acelerador e do grau em que estes objetivos são adequados com as necessidades dos financiadores. Compreender a dinâmica desse tipo de rede colaborativa contribui para a gestão estratégica da informação, em consonância com Inomata (2017), pois influi de acordo com Sena, Cândido, e Blattmann (2020), na busca por aderir maior qualidade no processo de incubação (leia-se aceleração nesta pesquisa) em ambientes de inovação, por intermédio de serviços gerados pelas startups a serem utilizados pela sociedade.

Dessa forma, evidencia-se a importância da investigação descrita neste artigo, quando da análise das startups apresentadas no site startupbase.com, a partir do mapeamento da influência delas no cenário brasileiro.

\section{METODLOLOGIA}

Esta pesquisa apresenta caráter exploratório e descritivo, com abordagem qualitativa dos dados. Para sua realização, selecionou-se a base de dados StartupBase.com (2020), atualizada em tempo real, concentrada numa plataforma aberta para consulta pública, com dados sobre o ecossistema das startups e conteúdo das informações demográficas e quantitativas, dados qualitativos, mercado e segmentos.

Utilizou-se também o site da Associação Brasileira de Startups (2021), na seção de "mapeamento de comunidades", que detalha o ecossistema de empreendedorismo por cada região do país, encontrando-se informação sobre 85 programas de aceleração e aceleradoras, destas, foram excluídas 48 aceleradoras, por não atenderem aos critérios de aceleração. Ressalta-se que as aceleradoras selecionadas são apoiadas por empresas públicas e empresas de tecnologia, assim, foram analisadas 37 aceleradoras, embora cinco das 37 aceleradoras não apresentaram informação sobre a quantidade de startups do programa de aceleração.

Os dados coletados no site Startupbase e Abstartups (ver Tabela 2) possibilitaram realizar uma comparação entre a quantidade de aceleradoras presentes nos ecossistemas de empreendedorismo e os números de startups aceleradas durante os diferentes Batch. As aceleradoras selecionadas atuam com o propósito principal de expandir os níveis da atuação das startups no mercado, cumprindo os objetivos de uma aceleradora de startups, qual seja: organizações que agilizam o crescimento de um negócio com poder de escalabilidade nos seus primeiros 
anos de vida com a finalidade de definir uma direção de forma metódica e clara, ou seja, "navegar com uma finalidade"(Andrade \& Monteiro, 2018).

\begin{tabular}{|c|c|c|c|c|}
\hline Item & Aceleradora & Foco de Ação & $\begin{array}{c}\text { Startups } \\
\text { Aceleradas }\end{array}$ & Link \\
\hline 01 & $\begin{array}{l}\text { Baita acelera- } \\
\text { dora }\end{array}$ & $\begin{array}{l}\text { Acelera startups de base tecnoló- } \\
\text { gica, com produtos, serviços ou } \\
\text { modelos de negócios disruptivos, } \\
\text { em fase inicial ou em crescimento }\end{array}$ & 48 & https://www.baita.ac/ \\
\hline 02 & Venture Hub & $\begin{array}{l}\text { Ajuda startups e grandes empre- } \\
\text { sas a liderarem o futuro de seus } \\
\text { mercados }\end{array}$ & 97 & http://venturehub.se/ \\
\hline 03 & $\begin{array}{l}\text { Criabiz Ven- } \\
\text { tures }\end{array}$ & Foco B2B e Inteligência de Dados & 11 & www.criabiz.com \\
\hline 04 & $\begin{array}{l}\text { Scale Endea- } \\
\text { vor Up }\end{array}$ & $\begin{array}{l}\text { Negócios de tecnologia que ofere- } \\
\text { çam produtos e serviços com foco } \\
\text { no consumidor final (B2C). Com } \\
\text { turmas abertas duas vezes ao ano, } \\
\text { o Scale-Up Endeavor é o maior } \\
\text { programa de aceleração para em- } \\
\text { presas de alto crescimento do } \\
\text { Brasil }\end{array}$ & $\begin{array}{c}\text { Sem } \\
\text { informação }\end{array}$ & https://endeavor.org.br/scaleu \\
\hline 05 & Overdrives & $\begin{array}{l}\text { Busca das melhores startups em } \\
\text { início de tração para juntos, de- } \\
\text { senvolver estratégias que gerem } \\
\text { valor relevante para cada negócio } \\
\text { e seu mercado alvo }\end{array}$ & 8 & $\begin{array}{c}\text { http://overdrives.com.br } \\
\text { /aceleracao/ }\end{array}$ \\
\hline 06 & CESAR.Labs & $\begin{array}{l}\text { Prioriza alguns segmentos de } \\
\text { mercado: o próprio TIC, varejo, } \\
\text { agricultura, saúde, educação, edi- } \\
\text { torial eletroeletrônico, automo- } \\
\text { tivo, robótica e biologia sintética }\end{array}$ & 11 & http://www.cesarlabs.com/ \\
\hline 07 & $\begin{array}{l}\text { InovAtiva } \\
\text { Brasil }\end{array}$ & $\begin{array}{l}\text { Em 2016, o Serviço Brasileiro de } \\
\text { Apoio às Micro e Pequenas Em- } \\
\text { presas (Sebrae) somou esforços } \\
\text { com o Ministério da Economia e } \\
\text { se tornou co-realizador, trazendo } \\
\text { capilaridade nas ações do pro- } \\
\text { grama pelo país }\end{array}$ & 1174 & $\begin{array}{l}\text { https://www.inovativabrasil. } \\
\text { com.br/sobre/ }\end{array}$ \\
\hline 08 & $\begin{array}{l}\text { Darwin Star- } \\
\text { tups }\end{array}$ & $\begin{array}{l}\text { Darwin, empresas e empreende- } \\
\text { dores têm acesso a dezenas de } \\
\text { benefícios avaliados em mais de } \\
\mathrm{R} \$ 500 \text { mil. Cloud Service, CRMs, } \\
\text { ferramentas de marketing }\end{array}$ & 46 & https://darwinstartups.com/ \\
\hline 09 & $\begin{array}{l}\text { O Instituto } \\
\text { Ekloos }\end{array}$ & $\begin{array}{l}\text { Apoia as empresas no desenvolvi- } \\
\text { mento de programas de Respon- } \\
\text { sabilidade Social, desde a constru- } \\
\text { ção da estratégia até o monitora- } \\
\text { mento, incluindo ações de volun- } \\
\text { tariado corporativo }\end{array}$ & 7 & www.ekloos.org \\
\hline 10 & Troposlab & $\begin{array}{l}\text { Somos uma aceleradora que en- } \\
\text { tende o que sua empresa precisa } \\
\text { para inovar }\end{array}$ & $\begin{array}{c}\text { Sem } \\
\text { informação }\end{array}$ & https://troposlab.com/ \\
\hline 11 & Startup RIO & $\begin{array}{l}\text { O StartupRio é o programa de ca- } \\
\text { pacitação e aceleração de empre- } \\
\text { endedores digitais da Secretaria } \\
\text { de Ciências, Tecnologia e Inova- } \\
\text { ção do Governo do Estado do Rio } \\
\text { de Janeiro }\end{array}$ & 19 & $\begin{array}{c}\text { http://www.startuprio.rj } \\
\text {.gov.br/ }\end{array}$ \\
\hline 12 & StartYouUP & $\begin{array}{l}\text { Foco no desenvolvimento de ne- } \\
\text { gócios inovadores e escaláveis }\end{array}$ & 11 & $\begin{array}{l}\text { http://www.startyouup. } \\
\text { com.br/ }\end{array}$ \\
\hline
\end{tabular}




\begin{tabular}{|c|c|c|c|c|}
\hline Item & Aceleradora & Foco de Ação & $\begin{array}{c}\text { Startups } \\
\text { Aceleradas }\end{array}$ & Link \\
\hline 13 & $\begin{array}{l}\text { Azys Inova- } \\
\text { ção }\end{array}$ & $\begin{array}{l}\text { Há } 6 \text { anos estamos ajudando a de- } \\
\text { senvolver projetos com nossa me- } \\
\text { todologia, vai ter um mapa da sua } \\
\text { jornada com opções de caminhos } \\
\text { e um guia que saberá como dire- } \\
\text { cionar você para um desenvolvi- } \\
\text { mento de alta performance }\end{array}$ & 11 & azys.com.br \\
\hline 14 & Sai do Papel & $\begin{array}{l}\text { Ajuda empreendedores e startups } \\
\text { a decolarem com seus negócios }\end{array}$ & 101 & https://www.saidopapel.com.b \\
\hline 15 & Quintessa & $\begin{array}{l}\text { O programa de aceleração é fo- } \\
\text { cado em estruturar a gestão e im- } \\
\text { pulsionar o crescimento de negó- } \\
\text { cios de impacto }\end{array}$ & 67 & https://www.quintessa.org.br/ \\
\hline 16 & Startup.farm & $\begin{array}{l}\text { Como o nome sugere, o Ahead } \\
\text { leva as startups muito além! } \\
\text { Permitindo-nos ajudar startups e } \\
\text { fundadores a se desenvolverem }\end{array}$ & 300 & https://startup.farm/ \\
\hline 17 & ACE & $\begin{array}{l}\text { Na ACE Startups, nossa missão } \\
\text { é fomentar o empreendedorismo } \\
\text { no país, acompanhando e desen- } \\
\text { volvendo os empreendedores ao } \\
\text { longo de sua jornada }\end{array}$ & 57 & https://acestartups.com.br/ \\
\hline 18 & $\begin{array}{l}\text { AgriHub } \\
\text { Space (em } \\
\text { construção) }\end{array}$ & $\begin{array}{l}\text { O 1hub de inovação do agrone- } \\
\text { gócio do Mato Grosso }\end{array}$ & 16 & $\begin{array}{l}\text { https://www.agrihubspace. } \\
\text { com.br/ }\end{array}$ \\
\hline 19 & Cotidiano & $\begin{array}{l}\text { O CAMP é um programa de } 12 \text { se- } \\
\text { manas, buscam um modelo de ne- } \\
\text { gócios escalável e repetível }\end{array}$ & 51 & https://cotidiano.com.br/ \\
\hline 20 & $\begin{array}{l}\text { Logo Cowor- } \\
\text { king e Acele- } \\
\text { radora }\end{array}$ & $\begin{array}{l}\text { O programa de aceleração de star- } \\
\text { tups da LOGO, elege como seu } \\
\text { foco estratégico em empresas ino- } \\
\text { vadoras de qualquer área de atua- } \\
\text { ção que tenha a tecnologia como } \\
\text { base }\end{array}$ & $\begin{array}{c}\text { Sem } \\
\text { informação }\end{array}$ & $\begin{array}{l}\text { https://www.logoaceleradora. } \\
\text { com.br/ }\end{array}$ \\
\hline 21 & Grow+ & $\begin{array}{l}\text { A GROW+ é uma aceleradora de } \\
\text { startups e gestora de investimen- } \\
\text { tos criada por empreendedores } \\
\text { obcecados em explorar novas for- } \\
\text { mas de fazer negócios por meio } \\
\text { da inovação }\end{array}$ & 150 & https://growplus.com.br/ \\
\hline 22 & Ventiur & $\begin{array}{l}\text { Sempre voltado para as necessi- } \\
\text { dades do setor produtivo, o BRDE } \\
\text { tem como um de seus objetivos } \\
\text { estratégicos a promoção do ecos- } \\
\text { sistema de inovação da Região Sul }\end{array}$ & 12 & https://ventiur.net/ \\
\hline 23 & WOW & $\begin{array}{l}\text { A WOW é uma aceleradora dife- } \\
\text { rente. Nosso programa é mantido } \\
\text { por um grupo de mais de } 220 \text { in- } \\
\text { vestidores, que estão totalmente } \\
\text { comprometidos com o sucesso } \\
\text { das nossas empresas aceleradas }\end{array}$ & 156 & https://www.wow.ac/ \\
\hline 24 & $\begin{array}{l}\text { STARS Acele- } \\
\text { radora }\end{array}$ & $\begin{array}{l}\text { A Stars é uma aceleradora que } \\
\text { busca estruturar negócios al- } \\
\text { tamente escaláveis, visando o } \\
\text { maior desenvolvimento socio- } \\
\text { econômico ao ecossistema de } \\
\text { inovação }\end{array}$ & 5 & $\begin{array}{c}\text { https://starsaceleradora. } \\
\text { com.br/ }\end{array}$ \\
\hline
\end{tabular}




\begin{tabular}{|c|c|c|c|c|}
\hline Item & Aceleradora & Foco de Ação & $\begin{array}{c}\text { Startups } \\
\text { Aceleradas }\end{array}$ & Link \\
\hline 25 & HOTMILK & $\begin{array}{l}\text { A Hotmilk foi criada em } 2014 \text { pela } \\
\text { PUCPR com o propósito de ser } \\
\text { um agente de mudança da socie- } \\
\text { dade, queremos que o processo } \\
\text { de criação e desenvolvimento da } \\
\text { sua startup seja uma experiência } \\
\text { de impacto }\end{array}$ & 98 & $\begin{array}{l}\text { http://hotmilk.pucpr.br } \\
\text { /aceleradora/ }\end{array}$ \\
\hline 26 & Libria & $\begin{array}{l}\text { Projetos podem gerar lucro e be- } \\
\text { nefícios socioambientais, através } \\
\text { da criação de novos paradigmas } \\
\text { para o futuro }\end{array}$ & 14 & http://www.projetolibria.com.br/ \\
\hline 27 & Evoa & $\begin{array}{l}\text { Empresas que acreditam no po- } \\
\text { tencial de novas ideias e que bus- } \\
\text { cam resolver problemas junto às } \\
\text { startups ou através de seus cola- } \\
\text { boradores }\end{array}$ & 20 & https://www.evoa.com.br/ \\
\hline 28 & Orbital & $\begin{array}{l}\text { Ajudamos empreendedores a } \\
\text { crescerem seus negócios nessa } \\
\text { nova era, potencializando para } \\
\text { modelos exponenciais e evitando } \\
\text { erros na sua jornada }\end{array}$ & 19 & https://www.orbital.ac/ \\
\hline 29 & Spin & $\begin{array}{l}\text { A Spin acredita que startups criam } \\
\text { conexões de valor para a transfor- } \\
\text { mação digital de Indústrias }\end{array}$ & 68 & https://spin.capital/ \\
\hline 30 & $\begin{array}{l}\text { Casa Azul } \\
\text { Ventures }\end{array}$ & $\begin{array}{l}\text { A Casa Azul Ventures é uma ace- } \\
\text { leradora de startups que investe } \\
\text { em empreendedores fodas, re- } \\
\text { solvendo grandes problemas em } \\
\text { mercados muito relevantes }\end{array}$ & 4 & https://www.casaazul.vc/ \\
\hline 31 & Belabs & $\begin{array}{l}\text { Apoiando MULHERES EMPRE- } \\
\text { ENDEDORAS no desenvolvi- } \\
\text { mento e aceleração de novas } \\
\text { ideias e negócios }\end{array}$ & $\begin{array}{c}\text { Sem } \\
\text { informação }\end{array}$ & http://belabs.org/ \\
\hline 32 & ICC BioLabs & $\begin{array}{l}\text { Objetivo de criar e desenvolver } \\
\text { soluções avançadas com foco na } \\
\text { melhoria da qualidade de vida do } \\
\text { ser humano }\end{array}$ & 25 & http://waveaccelerator.com/ \\
\hline 33 & Incubatech & $\begin{array}{l}\text { A Incubatech é uma empresa de } \\
\text { aceleração de startups com foco } \\
\text { no desenvolvimento de softwa- } \\
\text { res sob medida e que busca trans- } \\
\text { formar ideias em negócios rentá- } \\
\text { veis, estimulando o empreende- } \\
\text { dorismo e a inovação }\end{array}$ & 7 & https://www.incubatech.com.br/ \\
\hline 34 & Acelerase & $\begin{array}{l}\text { Somos uma aceleradora de star- } \\
\text { tups e um hub de inovação a par- } \\
\text { tir de Sergipe, região nordeste do } \\
\text { Brasil. Somos conduzidos pelo } \\
\text { propósito desenvolver empreen- } \\
\text { dedores, acelerar ideias e promo- } \\
\text { ver inovação }\end{array}$ & $\begin{array}{c}\text { Sem } \\
\text { informação }\end{array}$ & http://www.acelera.se/ \\
\hline 35 & $\begin{array}{l}\text { FabriQ Ace- } \\
\text { leradora }\end{array}$ & $\begin{array}{l}\text { Primeira Aceleradora, do Norte } \\
\text { do Brasil, acreditamos e fomenta- } \\
\text { mos o empreendedorismo digital } \\
\text { em nossa região }\end{array}$ & 31 & http://aceleradora.fabriq.com.br/ \\
\hline
\end{tabular}




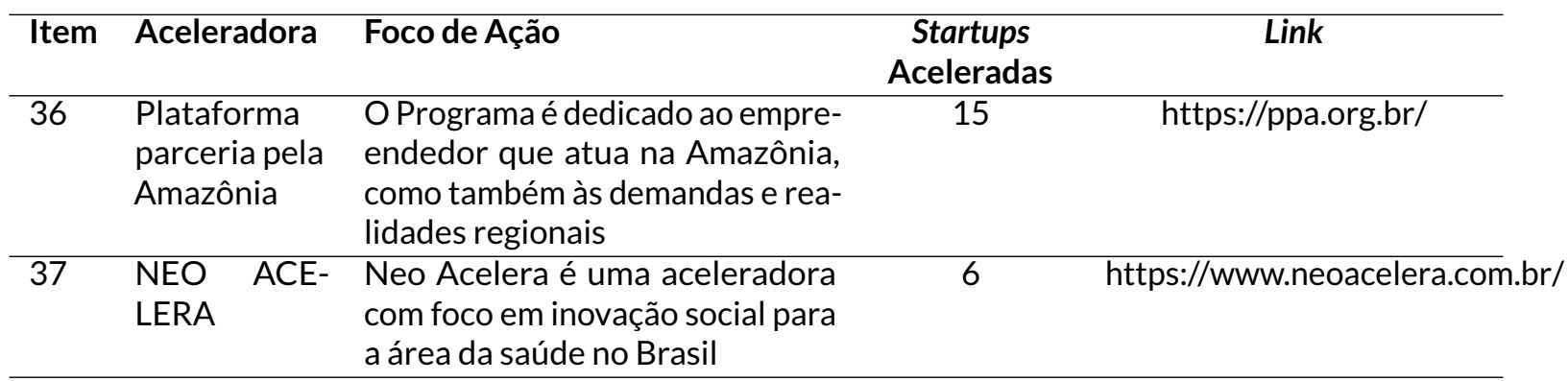

Tabela 2. Mapeamento das aceleradoras de startups no Brasil.

A partir das startups submetidas na base de dados startupbase.com, verifica-se a importância de melhorar os canais de comunicação da educação tradicional na sociedade brasileira, em que a área da educação representa 8,31\% das startups desenvolvidas no país das 13.297 startups pesquisadas.

Nesse nicho de mercado, encontramos a startup Arco Educação, que tem como missão transformar a forma como os estudantes aprendem, promovendo a educação de excelência, sendo uma das empresas digitais brasileiras com valor de US $\$ 2,8$ bilhões, e com um grupo de 936 funcionários.

\section{ANÁLISE DOS RESULTADOS}

A Tabela 2 demostra os resultados gerais da análise quantitativa de aceleradoras brasileiras, destacando: área de ação, nicho de mercado e número de startups impactadas, assim, foi possível encontrar as aceleradoras de destaque no mercado brasileiro, aquelas que demonstram fatores necessários para levar startups ao roll dos gigantes.

O processo de seleção e as características das startups selecionadas influenciam o sucesso do próprio acelerador. Alguns dos critérios de seleção para as startups geralmente são baseados em: 1) Potencial de lucro de vendas; 2) Restrições políticas e sociais; 3) Potencial de crescimento; 4) Análise da concorrência; 5) Distribuição de risco e; 6) Reestruturação da indústria. A fase final foca em critérios, tais como: gestão, capital, competência de produção, marketing e distribuição, apoio técnico, e disponibilidade de materiais ou componentes.

$\mathrm{Na}$ "civilização tecnológica", as startups procuram preencher o espaço entre os vendedores e consumidores, encontrando grandes oportunidades na tecnologia para levar maiores benefícios à sociedade. A justificativa é que o homem é, ao mesmo tempo, produtor e consumidor e, assim, no ato do consumo, cada classe irá satisfazer-se de acordo com o seu grau de aquisição (Morin, 2010).

As startups podem acrescentar ferramentas de aquisição dos produtos e serviços por intermédio das inovações tecnológicas a gerar uma aparência de conforto, na qual as pessoas podem sentir-se inseridas no comércio global. A startup Stone desenvolveu uma plataforma de gestão, acesso a empréstimos, conta para pessoa jurídica e planos para a fidelização dos clientes, um processo tecnológico que oferece um serviço completo, sendo seu diferencial junto às demais startups.

Para Ries (2011, p. 13), startup "é uma instituição humana projetada para criar produtos e serviços em condições de extrema incerteza, com propósito é ser empresas altamente escaláveis, as avaliações estão muitas vezes alicerçadas nas perspectivas de crescimento".

Atingir a maior cobertura de usuários por meio do uso das suas inovações tecnológicas requer um aumento significativo nos recursos econômicas das startups. O setor de capitalismo de risco, ou Venture Capitalism, focado no financiamento de startups, socorre muitas das necessidades econômicas que elas vivem.

Startups com rodadas de financiamento maior a US $\$ 1$ bilhão num tempo de máximo 10 anos, desenvolvem o conceito de unicórnio no ecossistema de empreendedorismo digital. A indústria que mais tem atraído capital de risco e gerado startups unicórnios no Brasil estão no setor da Fintech. São startups de tecnologia para setor de serviços financeiros, o exemplo mais representativo do setor é o Nubank, que inclusive entre os Decacórnios, título reservado para as startups avaliadas em mais de US\$10 bilhões. Só há outros 22 no mundo auxiliando o desenvolvimento e expansão de empresas (Mendes, 2019). Contudo, as startups PagoSeguro, Stone e Ebanx também são consideradas startups unicórnios do Brasil e são também da fintech.

A inovação no setor das finanças traz benefícios para a sociedade e pode permitir maior segurança para as pessoas, redução de custos bancários e ganho de tempo na realização de todo tipo de transações. Em virtude dessas características, a aceleradora Scalap Endevor Up (Tabela 2) investe na startup Neon, que durante os últimos quatro anos, foi pioneira em diversas inovações relacionadas à digitalização dos serviços financeiros (Conrad, 2020). Neon tem perspectivas de crescimento e se posicionar como um novo unicórnio do país. 
Scalap Endevor Up consegue representar de melhor forma o conceito que Gregori e Holzmann (2020) abordaram sobre a importância das aceleradoras nos ecossistemas de empreendedorismo, contribuindo para o uso de tecnologias digitais, para a captura de valor multidimensional e para levar uma empresa da fase inicial para a fase comercial, ajudando com as ferramentas necessárias para se tornar uma startup unicórnio no Brasil.

Para Bill Gross, fundador da IdeaLab, uma das primeiras incubadoras americanas, os principais objetivos dos unicórnios são: ter uma ideia inovadora, um time eficaz, um modelo de negócio bem traçado, disponibilidade de capital e timing. Sua conclusão: acertar o momento em que as pessoas estão preparadas para consumir uma nova ideia é o maior responsável pelo sucesso de uma startup (Estudo..., 2020).

Ainda assim, menos de $1 \%$ das startups que recebem investimentos de venture capital chegam ao valuation bilionário, e várias quebram mesmo depois disso. Muitas vezes, os valuations são estabelecidos por investidores e venture capitals por intermédio de previsões de longo prazo que tem mais base na impressão de como a empresa crescerá do que em seu desempenho financeiro atual (Quandt, 2020).

Embora a saída via Initial Public Offering (IPO) ou aquisição seja frequentemente usada na literatura de finanças empreendedoras como uma medida de sucesso de inicialização, dada a novidade do fenômeno acelerador e a oportunidade cada vez maior para sair de startups apoiadas no capital de risco na última década, é provável que seja cedo demais para usar essa opção de saídas como medida de sucesso para empreendedores iniciantes de aceleração (Cohen et al., 2019).

O mercado brasileiro demonstra uma grande voracidade para as chamadas transações de fusões e aquisições de startups. O ano de 2020 destaca-se como o de maior número de fusões e aquisições de startups brasileiras, totalizando 54 entre julho e setembro, sendo 21 apenas em setembro, mais adiante dos investimentos oriundos das operações de fusões e aquisições, as startups brasileiras também receberam US $\$ 843$ milhões em financiamentos de empresas de capital de risco em setembro - valor $65 \%$ superior ao registrado em setembro do ano passado. No ano de 2020, o valor acumulado já chega a US\$ 2,2 bilhões, distribuídos em 322 rodadas. Porém, quanto ao volume investido, a maior parte encontra-se em fase tardia (Série A - G e Private Equity). Mais de $90 \%$ do capital investido (US\$ 2,1 bilhões) está concentrado nessas etapas (Fuões..., 2020).

Uma inovação é uma ideia, comportamento ou objeto percebido como novo por seu público. A difusão de inovações oferece três percepções valiosas sobre o processo de mudança social, de acordo com Startup Awards, no ano 2016 foi escolhido a aceleradora InovAtiva Brasil como a melhor aceleradora do Brasil. Em seu portfólio, encontram-se startups como PluriCell Biotech, que desenvolve terapias celulares baseadas em células-tronco pluripotentes. Atualmente, está focada em desenvolver terapias para pacientes com problemas cardíacos, mais especificamente insuficiência cardíaca congestiva. Apoiados na hipótese que terapia celular é o futuro da medicina regenerativa, mais de 1.174 startups já foram aceleradas pela InovAtiva.

Em 2017 a Startup Farm foi eleita com votação aberta a melhor acelerada dentro de Start-up Awards. Representação do esforço ao longo dos seis últimos anos de atividade e mais de 270 startups aceleradas, com uma proposta simples: oferecem um programa de aceleração (inúmeros conteúdos, materiais, suporte e tudo aquilo descrito lá em cima) e, em troca, as startups cedem $5 \%$ do equity, com um investimento até R $\$ 150$ mil de investimento.

Durante os anos 2018, 2019 e 2020 uma aceleradora com foco nas áreas deFintech, Big Data E Analytics, Telecom e TI, foi a premiada com o prêmio Startup Awards, a melhor aceleradora do país, Darwin Startups, onde o modelo de negócio tem como alvo inicial um investimento até $\mathrm{R} \$ 200$ mil em troca de $7 \%$ da startup. O que denota a compreensão que o apoio financeiro e humano tem impactos positivos, e reforça a importância de fomentar ambientes inovadores que proporcionem segurança como fonte de informações a alavancar esse tipo de empresa em seus estágios iniciais.

\section{CONSIDERAÇÕES}

A pesquisa teve como objetivo principal analisar a situação atual das startups e o impacto das aceleradoras no ecossistema de empreendedorismo. Destaca-se que o maior campo de ação das startups brasileiras está na área de educação, sendo 8,31\% do total das startups no país. A tecnologia traz crescimento e desenvolvimento às sociedades contemporâneas, podendo ser utilizada para que todos os seres humanos se beneficiem e integrem-se nessa mesma sociedade, mas tornam-se essenciais mudanças substanciais nos canais de educação no país apoiados na tecnologia.

É relevante que os empreendedores, além de observarem uma oportunidade de negócio, tenham o compromisso de melhorar a educação no país, a fim de mudar a sociedade: como exemplo a Arco Educação, cuja missão é transformar a educação por meio da tecnologia como uma importante ferramenta para potencializar tanto a gestão, quanto o processo pedagógico das escolas, conectando as pessoas, gerando dados e viabilizando trilhas de aprendizagem cada vez mais personalizadas e adaptadas, com intenção de formar um país melhor para as crianças e jovens do mundo. 
Ressalta-se que com investimento de até $\mathrm{R} \$ 200$ mil reais, em troca de $7 \% *$ da startup, aceleradoras como Darwin, poderiam ter investimentos de até $\mathrm{R} \$ 9,200,000$ em seu portfólio de 46 startups. Esses recursos têm o potencial de expandir as startups tanto com conhecimentos especializados quanto para resolver os problemas que estão experimentando ou experimentarão no futuro. Além disso, menos de $1 \%$ das startups que recebem investimentos de venture capital chegam ao valuation bilionário. Várias empresas quebram nesse processo, mesmo assim o ecossistema de startups, apoiado pelas aceleradoras, ainda é capaz de propiciar a criação de empregos, que fomentam o desenvolvimento das economias locais.

Dessa forma, esta pesquisa soma a crescente literatura sobre o ecossistema de empreendedorismo digital no Brasil, no que concerne aos benefícios que as aceleradoras agregam ao ecossistema de startups. Uma vez que se realizou o mapeamento das áreas de ação das startups no país, com nove unicórnios no Brasil e 1.397 sstartups submetidas na base de dados de startupsbase.com.br. O trabalho integrado de aproximadamente 37 aceleradoras no país tem o potencial de trazer mais investimentos aos hubs de inovação.

Por fim, acredita-se que esta pesquisa contribui teoricamente devido ao fato de apresentar um panorama sobre o empreendedorismo digital no Brasil, particularmente nos novos contextos das aceleradoras sob a perspectiva da Ciência da Informação e suas características voltadas para a produção, o registro, a organização, a representação, a distribuição, a recuperação, o acesso e a apropriação da informação. 


\section{REFERÊNCIAS}

Andrade, I. A., \& Monteiro, S. D. (2018). Diretrizes para busca de informação no ciberespaço; directrices para la búsqueda de información en el ciberespacio. Informação Profissões, 1(1/2), 187-203. doi: 10.5433/23174390.2012v1n1/2p186

Associação Brasileira de Startups. (2021). Sobre. Recuperado de https://abstartups.com.br/sobre/

Capurro, R., \& Hjørland, B. (2007). O conceito de informação. Perspectivas em Ciência da Informação, 12(1), 148-207. doi: 10.1016/S0149-2063(96)90021-5

Cohen, S., Fehder, D. C., Hochberg, Y. V., \& Murray, F. (2019). The design of startup accelerators. IEEE Transactions on Engineering Management, 48(7), 1781-1797. doi: 10.1016/j.respol.2019.04.003

Conrad, P. (2020). Sobre a empresa. Recuperado de https:// endeavor.org.br/empresa/neon/

Distrito. (2019). Hub de inovação é essencial para conectar empresas e startups. Recuperado em 2019, dezembro, de https://distrito.me/hub-de-inovacao/\#: : text $=$ hubs $\% 20$ de $\% 20$ inova $\%$ C3\%A7\%C3\%A3o-,O\% 20que\%20\% C3\%A9\%20hub\%20de\%20inova \% $3 \%$ A7\% C3\%A3o,grandes\%20empresas\%20e\%20outras\%20startups

Estudo... (2020). Estudo do mercado de startups unicórnios no brasil, previsões para novas unicórnios do pais e venture capital. How Education Medium. Recuperado de https://howeducation.medium.com/ estudo-do-mercado-de-startups-unic\% C3\%B3rnios-no -brasil-previs\%C3\%B5es-para-novas-unic\%C3\%B3rnios-do -pa\%C3\%ADs-f2723459f38b

Friedman, B. A., \& Aziz, N. (2012). Turkey and the united states: Entrepreneurship activity, motives, aspirations, and perceptions. International Journal of Business and Social Science, 3(3), 96-107. Recuperado de http://citeseerx.ist.psu.edu/viewdoc/download?doi=10 $1 \cdot 1 \cdot 1062.4524 \&$ rep $=$ rep $1 \&$ type $=$ pdf

Fuões... (2020). Fusões e aquisições de startups brasileiras batem recorde em 2020. Olhar Digital. Recuperado de https://olhardigital.com.br/2020/10/01/noticias/fusoes-e -aquisicoes-de-startups-brasileiras-batem-recorde-em-2020/

Gregori, P., \& Holzmann, P. (2020). Digital sustainable entrepreneurship: a business model perspective on embedding digital technologies for social and environmental value creation. Journal of Cleaner Production, 272(122817). doi: 10.1016/j.jclepro.2020.122817

Inomata, D. O. (2017). Redes colaborativas e ambiente de inovação: uma análise dos fluxos de informação (Tese de doutorado, Universidade Federal de Santa Catarina, Florianópolis, Brasil). Recuperado de http://tede.ufsc.br/teses/ PCIN0163-T.pdf

Lamine, W., Mian, S., Fayolle, A., Wright, M., Klofsten, M., \& Etzkowitz, H. (2018). Technology business incubation mechanisms and sustainable regional development. Journal of Technology Transfer, 43, 1121-1141. doi: 10.1007/s10961016-9537-9

Mendes, E. (2019). Nubank é a primeira fintech do brasil a se tornar um "decacórnio". Olhar Digital. Recuperado de https://seucreditodigital.com.br/nubank-e-a -primeira-fintech-decacornio/

Morgan, N. A. (2012). Marketing and business performance. Journal of he Academy of Marketing Science, 40(1), 102119.
Morin, E. (2010). Ciência com consciência (13a. ed.). Rio de Janeiro: Bertrand Brasil.

Quandt, D. (2020). Conclusão. In Corrida dos Unicórnios. Distrito. Recuperado de https://rdstation-static.s3.amazonaws.com/cms\%2Ffiles\% 2F65883\%2F1582222039Corrida_dos_Unicornios_2020 v9.pdf?utm_campaign $=$ resposta_automatica_ $\overline{\text { da }}$ _landing_page_dataminer_corrida_unicornios\&utm _medium $=$ email\&utm_source $=\mathrm{RD}+\overline{\mathrm{S}}$ tation

Ries, E. (2011). The lean startup: how today's entrepreneurs use continuous innovations to create radically successful businesses. New York: Crown Business.

Sebrae Nacional. (2016). Pesquisa gem revela taxa de empreendedorismo no país. Recuperado de https://www.sebrae.com.br/sites/PortalSebrae/bis/ pesquisa-gem-revela-taxa-de-empreendedorismo-no-pais ,eb3913c334085510VgnVCM1000004c00210aRCRD

Sena, P. M. B. (2020). Fontes de informação no ecossistema de startups de florianópolis (Tese de doutorado, Universidade Federal de Santa Catarina, Florianópolis,Brasil). Recuperado de https://tede.ufsc.br/teses/PCIN0226-T.pdf

Sena, P. M. B., Cândido, A. C., \& Blattmann, U. (2020). Profissionais brasileiras da Biblioteconomia no contexto das startups. In O protagonismo da Mulher na Biblioteconomia e Ciência da Informação: celebrando a contribuição intelectual e profissional de mulheres latino-americanas. Florianópolis: Rocha Editora e Gráfica. Recuperado de https:// 3b2d7e5d-8b9a-4847-aa3e-40931d588fb7.filesusr.com/ugd/ c3c80a_6a390ea433624e6e90df1c1a34e72706.pdf

Shane, S. (2020). Explaining variation in rates of entrepreneurship in the united states: 1899-1988. Journal of Management, 22(5), 747-781. doi: 10.1016/S0149-2063(96)90021-5

Shenkoya, T. (2020). A study of startup accelerators in silicon valley and some implications for nigeria. African Journal of Science, Technology, Innovation and Development, 13(3), 1-12. doi: 10.1080/20421338.2020.1746045

StartupBase.com. (2020). Fusões e aquisições de startups brasileiras batem recorde em 2020. Recuperado de https:// startupbase.com.br/home

Travers, P. K., \& Teixeira, C. S. (2017). As características definidoras das aceleradoras e suas diferenças para outras organizações filantrópicas. Revista Eletrônica do Alto Vale do Itajaí, 6 (9), 98-107. doi: 10.5965/2316419006092017098

Yin, B., \& Luo, J. (2018). How do accelerators select startups? shifting decision criteria across stages. IEEE Transactions on Engineering Management, 65(4), 574-589. doi: $10.1109 /$ TEM.2018.2791501

Como citar este artigo (APA):

Garcia Arcentales, J. J., Sena, P. M. B. \& Araujo, N. C. de (2021). O papel das aceleradoras para o desenvolvimento das startups e do empreendedorismo no Brasil. AtoZ: novas práticas em informação e conhecimento, 10(3), 1-11. Recuperado de: http:// dx.doi.org/10.5380/atoz.v10i3.80186 